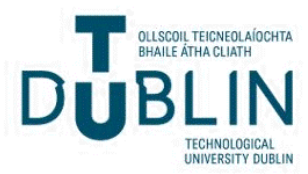

Technological University Dublin ARROW@TU Dublin

\section{A Novel Wideband Semi-planar Miniaturized Antenna}

\author{
Giuseppe Ruvio \\ Technological University Dublin \\ Max Ammann \\ Technological University Dublin, max.ammann@tudublin.ie
}

Follow this and additional works at: https://arrow.tudublin.ie/engscheceart

Part of the Electrical and Computer Engineering Commons

\section{Recommended Citation}

Ruvio, G., Ammann, M.: A novel wideband semi-planar miniaturized antenna. IEEE Transactions on Antennas and Propagation, Vol.55, issue 10, pp.2679-2685. 2007. doi:10.1109/TAP.2007.905844

This Article is brought to you for free and open access by the School of Electrical and Electronic Engineering at ARROW@TU Dublin. It has been accepted for inclusion in Articles by an authorized administrator of ARROW@TU Dublin. For more information, please contact arrow.admin@tudublin.ie, aisling.coyne@tudublin.ie, gerard.connolly@tudublin.ie.

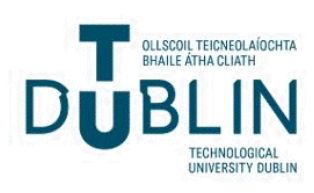


Dublin Institute of Technology

ARROW@DIT

Conference papers

School of Electronic and Communications

Engineering

2007-01-01

\section{A novel wideband semi-planar miniaturized antenna}

Giuseppe Ruvio

Dublin Institute of Technology

Max Ammann

Dublin Institute of Technology, max.ammann@dit.ie

\section{Recommended Citation}

Ruvio, G. and Ammann, Max: A novel wideband semi-planar miniaturized antenna. IEEE Transactions on Antennas and Propagation,St. Petersburgh, Russia,October, 2007, Vol.55, issue 10, pp.2679-2685

This Article is brought to you for free and open access by the School of Electronic and Communications Engineering at ARROW@DIT. It has been accepted for inclusion in Conference papers by an authorized administrator of ARROW@DIT. For more information, please contact yvonne.desmond@dit.ie, arrow.admin@dit.ie. 


\title{
A Novel Wideband Semi-Planar Miniaturized Antenna
}

\author{
Giuseppe Ruvio and M. J. Ammann, Member, IEEE
}

\begin{abstract}
A semi-planar miniaturized antenna which operates over the FCC allocated UWB spectrum is presented. The small antenna comprises a folded conducting element connected to a printed section. Several solutions are introduced which create different current paths increasing the effective dimensions of the antenna. The antenna is examined for the stand-alone case and for the antenna mounted in various locations on a larger handset-type groundplane. The impedance and radiation characteristics show a relative independence of the groundplane size and the antenna location on it. The proposed antenna is a valuable candidate for handset applications due to its compactness. The proposed antenna may be employed in UWB communications systems and exhibits quasi-omnidirectional radiation patterns over the full impedance bandwidth.
\end{abstract}

Index Terms-Beveling, folded planar monopole antenna, microstripline-feed, miniaturization, ultrawideband (UWB).

\section{INTRODUCTION}

$\mathbf{T}$ HERE has been a proliferation of research on small wideband antennas since the Federal Communication Commission (FCC) allocated a bandwidth of $7.5 \mathrm{GHz}(3.1-10.6$ $\mathrm{GHz}$ ) for ultrawideband (UWB) applications. Monopole antennas have successfully provided broad impedance bandwidth with good omnidirectional features in terminal devices. These unbalanced antennas are also conveniently matched to $50 \Omega$. In an effort to minimize manufacturing costs and improve bandwidth, planar structures have been developed in order to replace the classical quarter-wave cylindrical stub [1], [2]. Planar monopole antennas have been optimized to provide extremely wide impedance bandwidths with decent radiation characteristics [3], [4]. Moreover, the research community has diverted part of its efforts to develop very compact UWB antennas for portable applications. These requirements have stimulated the design of more complex shaped monopolar antennas offering good compromises between overall efficiency and compactness [5], [6]. Planar inverted-F antennas (PIFA) have been demonstrated to be excellent candidates to meet the needs for handset devices in broadband systems [7], [8]. In effect, the insertion of shorting probes enhances the impedance bandwidth performance as they introduce more complex current paths, which allow the excitation of more modes within

Manuscript received September 3, 2006; revised April 5, 2007. This work was supported by Science Foundation Ireland.

The authors are with the Centre for Telecommunications Value-chain Research, School of Electronic \& Communications Engineering, Dublin Institute of Technology, Dublin 8, Ireland (e-mail: giuseppe.ruvio@ student.dit.ie).

Color versions of one or more of the figures in this paper are available online at http://ieeexplore.ieee.org.

Digital Object Identifier 10.1109/TAP.2007.905844 the radiator. The particular folded shape of PIFAs reduces the size of the antenna even though this has a strong effect on the radiation pattern.

In this paper a compact wideband folded-shorted antenna is presented. It employs different impedance bandwidth enhancing techniques together to cover the entire UWB spectrum while retaining omnidirectional properties of this radiating element. The feed part of the antenna is printed on FR4 in order to get some of the benefits of printed circuit (PCB) technology, such as easier manufacturability and microstrip feeding. A key compact coplanar ground plane is fabricated on the same board, but on the opposite face of the feedline. The folded thin metallic sheet is connected to the printed element and shorted across the full length of the ground plane. Not only does this grounding solution significantly enhance the impedance bandwidth performance but also helps to mitigate the effect of the asymmetry due to the offset feed arrangement. The feed consists of a $50 \Omega$ microstrip feedline located asymmetrically at the base of the printed part of the radiator. An asymmetric bevel at the bottom edge of the antenna was optimized using the interpolated quasi Newton method to improve the match of the structure. A shorting probe, typical of PIFA technology, connects the printed structure to the folded external part of the antenna. This pin introduces an alternative current path that allows a reduction of the distance between the FR4 and the folded plate element, thus reducing the antenna volume. In addition to that, the external part of the antenna is shaped in such a way that a more complex current path is provided for the currents flowing along the side edge of the structure. This technique of miniaturization based on the insertion of complex resonating profiles allows a virtual enlargement of the electrical dimensions of the structure without modifying its overall physical dimensions. The multiple edges of the folded external element permit matching at lower frequencies of the spectrum while the physical dimensions of the antenna are kept compact. In addition to the UWB impedance bandwidth, the small size and the useful omnidirectional features offered, the performance of this antenna remains satisfactory when positioned on a large ground plane. The antenna proposed was tested as a stand-alone antenna and also when positioned in four different configurations, mounted on a larger ground plane typical of portable terminals/handsets. Both impedance and radiation performances offer considerable potential and are described in the next sections of the paper.

The different solutions introduced for the proposed antenna have been optimized by using the finite integration time domain method. The optimization goal was defined in terms of both impedance bandwidth and radiation characteristics. On the basis of these numerical results obtained by CST Microwave 
Studio, prototypes were manufactured and tested. An overall good agreement between experimental and numerical results was obtained.

\section{Design Evolution}

Many different techniques have been used to broaden the impedance bandwidth of monopole-type terminal antennas. An analysis of these techniques and the key parameters of the antenna have been treated in a comprehensive way [9]. In particular, the combined effects of introducing a bevel together with an offset feed arrangement were examined for a shorted folded planar monopole antenna. It is already shown in the literature that beveling the bottom border of planar monopolar antennas helps to shift upwards the upper edge (10 dB RL) frequency, thus increasing the impedance bandwidth [10]. Sometimes beveling techniques have been introduced together with an asymmetric feed in an attempt to increase the impedance bandwidth further [9], [10]. However, offset feed solutions could considerably affect the symmetry of the radiation pattern by introducing unwanted strong field components, which distort the omnidirectional behavior of the antenna. In [9], [11] it was demonstrated that the effects of the unbalanced currents (due to the offset and asymmetrical bevels in the feed arrangement) on the radiation properties of monopole can be mitigated when proper shorting solutions are adopted. Moreover, a solution to reduce the cost of the folded planar monopole antenna was introduced [11]. In fact, the combination of the PCB section (microstrip feed system and groundplane) and the shorted folded metallic sheet allows a significant reduction of both cost and size.

In the proposed antenna, these solutions have been employed and combined to the small novel element, thus allowing coverage of the entire FCC UWB spectrum and relative independence of the groundplane size and the antenna's location on it. Increased compactness has been also achieved by the insertion of a shorting via connecting the printed element to the external element and by complex indentation in the folded element, which is explained in the following sections. The total peripheral length of the external part is about half wavelength at the lower edge of the operating bandwidth. This comprises the system of slits which are symmetrically cut out from the external metallic element of the antenna. This length $(t+v 1+$ $6 v 2+8 x 1+v 3+v 5+6.4 \mathrm{~mm}$, see Fig. 1) must be increased in order to reduce the lower edge frequency further.

A numerical parametric sweep of the overall thickness $t$ of the antenna (from $t=4 \mathrm{~mm}$ to $10 \mathrm{~mm}$ ) has been made to analyze the effect of this parameter on the impedance bandwidth response of the antenna. A major effect has been noticed on the second and third resonance in the range of frequencies 2-12 $\mathrm{GHz}$; as the thickness $t$ increases they tend to overlap and constructively enlarge the $10 \mathrm{~dB}$ return loss bandwidth. At the same time, for larger values of $t$ the lower and top edge frequencies shift downwards from 3.47 to $3.08 \mathrm{GHz}$ and from 11.3 to 10.9 $\mathrm{GHz}$, respectively. A similar investigation has been carried out by sweeping the height $h(h=s 1+s 2)$ of the external metallic element while the thickness $t$ is kept fixed and equal to $8 \mathrm{~mm}$. In order to understand solely the effect of this geometric parameter, for this analysis the system of slits of the antenna has not

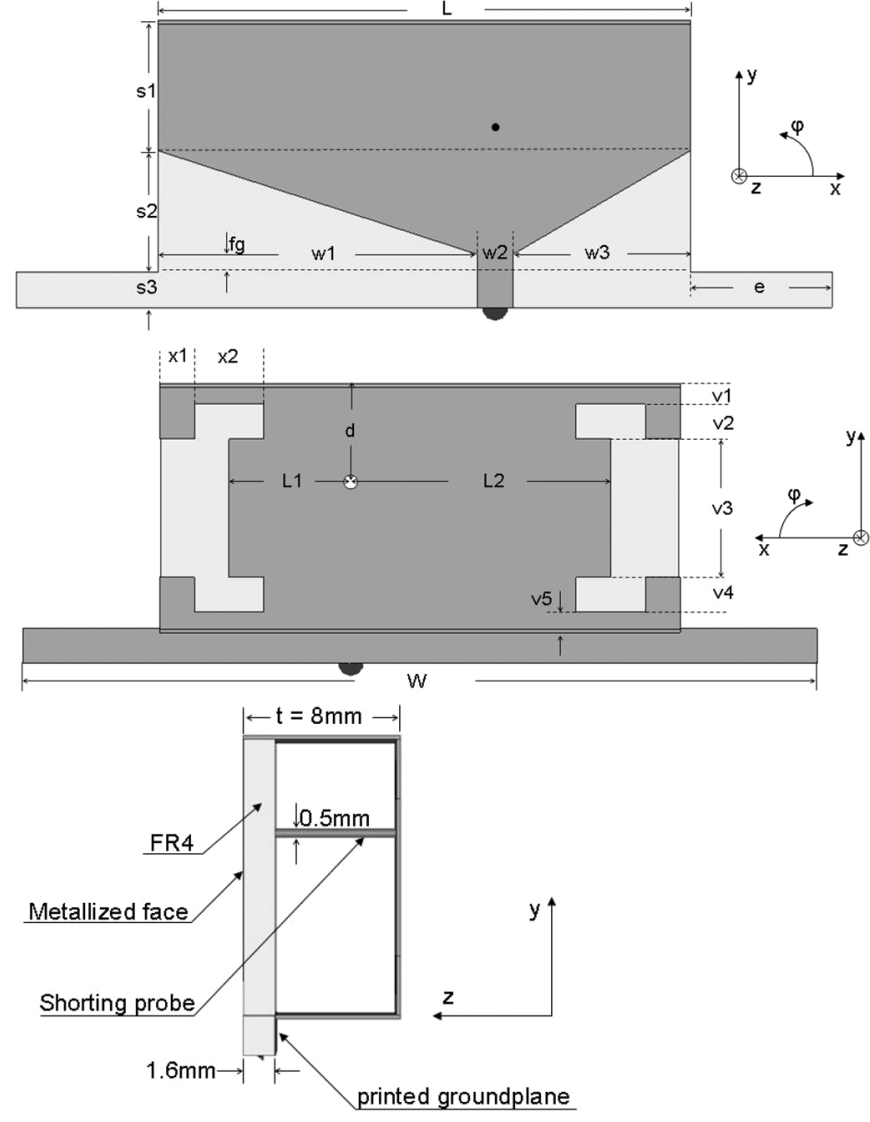

Fig. 1. Geometry of the antenna and coordinate system. $L=30 \mathrm{~mm}, L 1=$ $6.25 \mathrm{~mm}, L 2=14.75 \mathrm{~mm}, d=4.9 \mathrm{~mm}, s 1=7.5 \mathrm{~mm}, s 2=6.8 \mathrm{~mm}$, $s 3=2 \mathrm{~mm}, e=6 \mathrm{~mm}, w 1=18 \mathrm{~mm}, w 2=2 \mathrm{~mm}, w 3=10 \mathrm{~mm}$, $f g=1 \mathrm{~mm}, x 1=2 \mathrm{~mm}, x 2=4 \mathrm{~mm}, v 1=1.2 \mathrm{~mm}, v 2=2 \mathrm{~mm}$, $v 3=8 \mathrm{~mm}, v 4=2 \mathrm{~mm}, y 5=1.2 \mathrm{~mm}, W=46 \mathrm{~mm}$.

been included in the model simulated. As $h$ increases from 10.3 $\mathrm{mm}$ up to $17.3 \mathrm{~mm}$, the lower edge frequency shifts from 3.33 to $4.06 \mathrm{GHz}$. But a very minor effect can be seen on the upper edge frequency as this shifts from 11.485 to $11.5 \mathrm{GHz}$. Finally, the length $w$ of the ground plane has been swept and shown to play a dominant role on the operating bandwidth of the antenna. When $w$ increases from 30 up to $50 \mathrm{~mm}$, the lower edge frequency shifts from 3.53 down to $3.06 \mathrm{GHz}$ with a weaker effect on the upper edge frequency (i.e., from 10.51 to 10.76 $\mathrm{GHz}$ ). At the same time the two central resonances within the frequency range $2-12 \mathrm{GHz}$ tend to overlap with an optimum for $w=46 \mathrm{~mm}$. Hence, the width of the ground plane is the most critical parameter for the definition of the lower resonance in the resonance within the range $2-12 \mathrm{GHz}$. These results are summarized in Table I. Finally, Fig. 2 shows the comparison in terms of impedance bandwidth between the antenna with and without slits, respectively. This particular perimeter of the external element modifies the return loss pattern at lower frequencies without perturbing the higher part of the spectrum. In fact, the bottom edge frequency shifts down from $3.57 \mathrm{GHz}$ (with no slits) to $3.1 \mathrm{GHz}$ when slits are introduced.

\section{ANTENNA DESIGN}

The proposed antenna and coordinate system is shown in Fig. 1. The substrate used is low-cost FR4, which is $1.52 \mathrm{~mm}$ 
TABLE I

PARAMETRIC SwEEPS of $t, h$, AND $w$ AND THEIR EFFECT ON THE LOWER AND UPPER EDGE FREQUENCY OF THE 10 dB RETURN LOSS BANDWIDTH

\begin{tabular}{|c|c|c|c|}
\hline Parameter & $\begin{array}{c}\text { Parametric range } \\
{[\mathrm{mm}]}\end{array}$ & $\begin{array}{c}\text { Lower edge freq. } \\
\text { shift [GHz] }\end{array}$ & $\begin{array}{c}\text { Upper edge freq. } \\
\text { shift [GHz] }\end{array}$ \\
\hline$t$ & $4-10$ & $3.47-3.08$ & $11.3-10.9$ \\
\hline$h$ & $10.3-17.3$ & $4.06-3.33$ & $11.5-11.485$ \\
\hline$w$ & $30-50$ & $3.53-3.06$ & $10.76-10.51$ \\
\hline
\end{tabular}

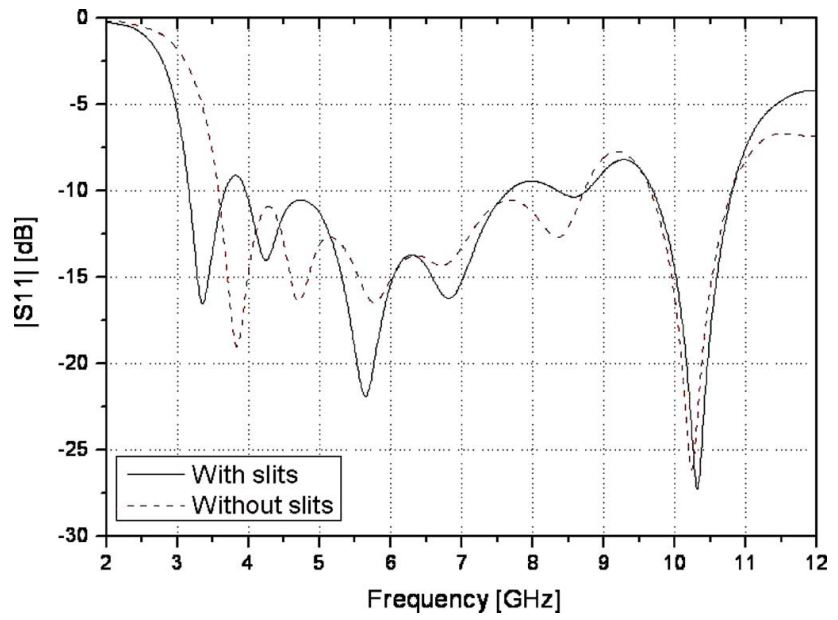

Fig. 2. Simulated impedance bandwidth for the antenna with and without slits.
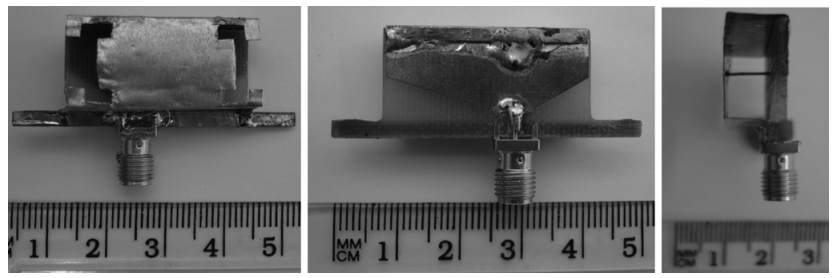

Fig. 3. Photos of the prototype manufactured, front, back and side view, respectively.

thick, with a relative permittivity of 4.3 and loss tangent of 0.02 . The external element is made of $0.2 \mathrm{~mm}$ brass sheet. A via of diameter $0.5 \mathrm{~mm}$ is used to connect the metallization on the PCB to the inner face of the folded part. In its stand-alone configuration, the antenna presented has just a small ground plane $(W=46 \mathrm{~mm} \times s 3=2 \mathrm{~mm})$, which is printed as shown in Fig. 1. All the other parameters that define the geometry of the antenna presented are listed in Fig. 1. Fig. 3 illustrates the prototype manufactured and tested.

In order to examine the behavior of the proposed compact antenna when mounted at different positions on a larger ground plane, a $100 \mathrm{~mm} \times 46 \mathrm{~mm}$ brass sheet was used and both a numerical and experimental analysis was made for the four different configurations. This larger groundplane is used to reproduce the effects, which are typical of small portable, fixed or handset configurations.

Fig. 4 illustrates the various configurations which are: (A) the antenna mounted in the middle of the large groundplane, (B) mounted on the longer side, (C) mounted on the shorter side of the large ground plane, and (D) mounted on top of the groundplane. The antenna was mounted on the large ground plane by connecting the small ground plane at the base of the radiator to

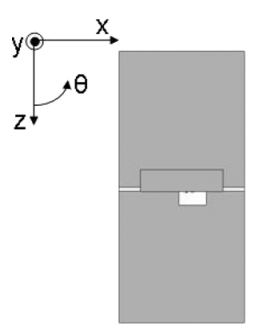

(A)

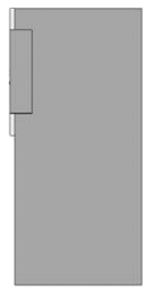

(B)

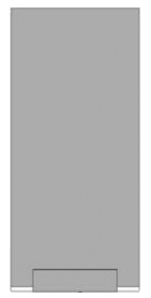

(C)

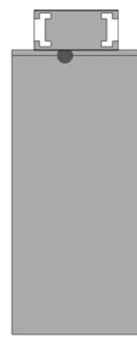

(D)
Fig. 4. Various layouts of antenna when located on larger groundplane.

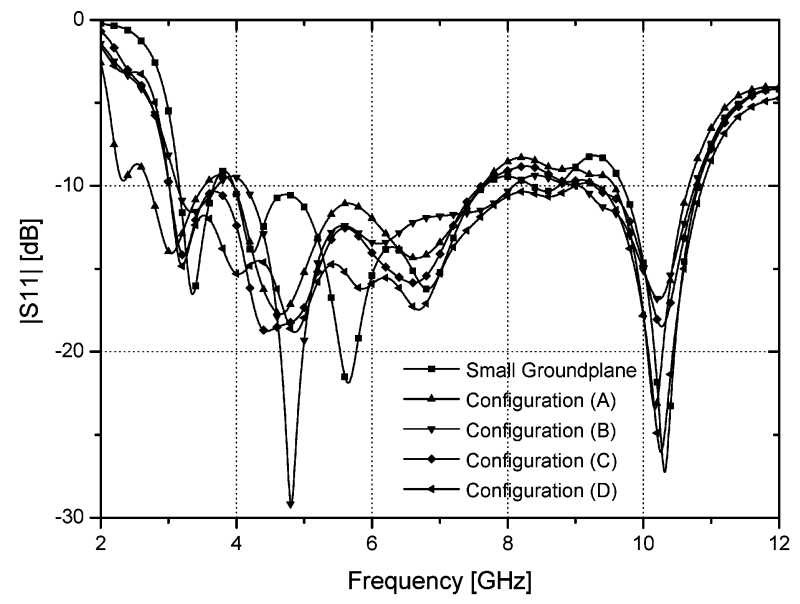

(a)

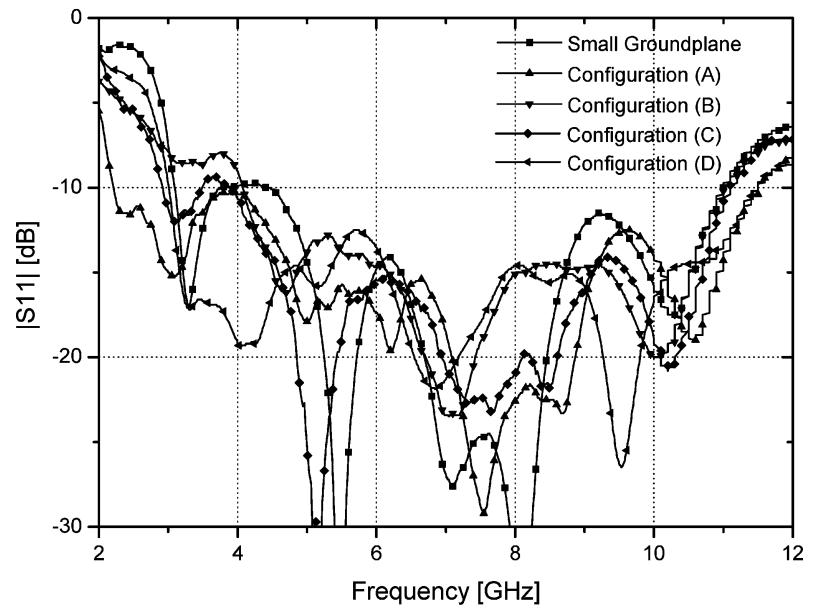

(b)

Fig. 5. Comparison of return loss for the antenna in all the configurations investigated. (a) Simulated and (b) measured results.

the large sheet. For the configuration (A) the coaxial connector feeding the antenna passes through a $10 \mathrm{~mm}$ by $10 \mathrm{~mm}$ slot cut out from the large ground plane. 


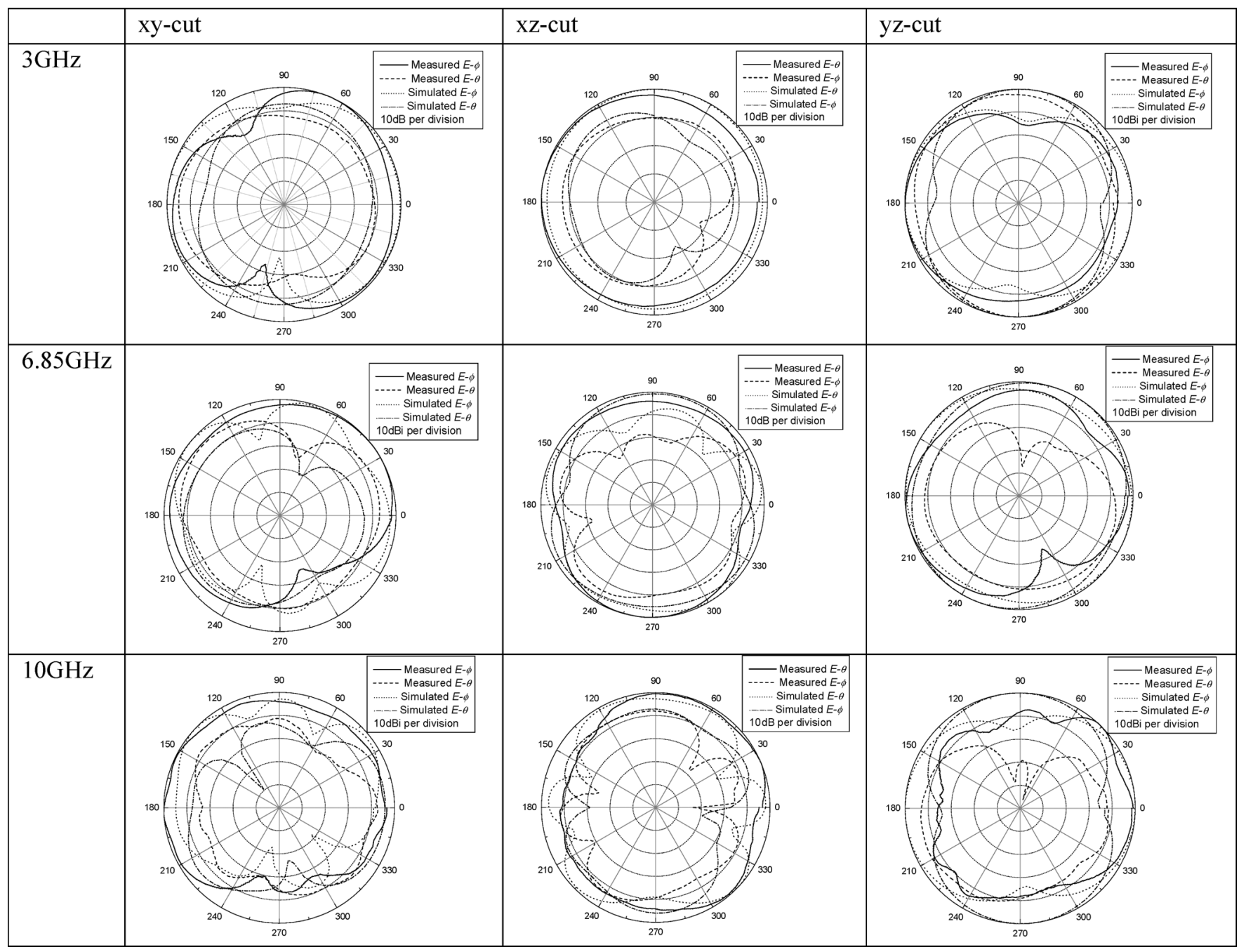

Fig. 6. Radiation patterns for the xy-, xz- and yz-cuts, respectively at 3, 6.85, and $10 \mathrm{GHz}$ for the antenna in the stand-alone configuration for copolar and crosspolar components.

\section{RESULTS AND DISCUSSION}

\section{A. Impedance Characteristics}

The proposed antenna in its stand-alone configuration (without large ground plane) has been numerically evaluated and experimentally verified. The simulated and measured return loss plots are shown in Fig. 5(a) and (b). A good agreement is achieved. Compared to the antenna presented in [11], the introduction of a system of slits cut away from the external conductive element is shown to successfully reduce the lower operating frequency, without increasing size or degrading the performance at higher frequencies. When the large groundplane is introduced according to the four configurations illustrated in Fig. 4, the return loss behavior obviously changes but the overall coverage of the UWB spectrum is still achieved as shown numerically and experimentally in Fig. 5(a) and (b), respectively. Only in the case of the configuration B (antenna attached at the corner of the longer side of the large ground plane) is the entire UWB band not entirely covered with a 10 $\mathrm{dB}$ return loss. In fact, the return loss rises by $2 \mathrm{~dB}$ above the $10 \mathrm{~dB}$ reference only between 3.1 and $4 \mathrm{GHz}$. Apart from this case, in all the other configurations the impedance bandwidth remains stable as the large ground plane is introduced in different positions. This feature suggests the possibility of using this antenna for portable terminal/handset applications, where the circuit board of the device itself behaves as a ground plane.

\section{B. Radiation Characteristics}

The radiation characteristics of the antenna were examined, firstly in its original stand-alone configuration and then when mounted on the large groundplane using the different configurations. Fig. 6 illustrates both measured and simulated radiation patterns at 3, 6.85 and $10 \mathrm{GHz}$ for the principle plane cuts ( $x y$, $x z$ and $y z$, respectively) for the antenna in its stand-alone configuration. Each pattern is presented in terms of co-polar and cross-polar components in a $10 \mathrm{~dB}$ scaled plot. The $x z$-cuts illustrate a decent omnidirectionality, especially in the lower part of the spectrum. From the other cuts ( $x y$ and $y z)$, it can be observed that the typical monopolar nulls are drastically reduced. However, a $20 \mathrm{~dB}$ null at $\Phi \approx 300^{\circ}$ is evident in the $x y$ - and $y z$-cut at $6.85 \mathrm{GHz}$. This is believed to be due to the hybrid working mode of the antenna at that frequency. This mode presents a combination of the effects of a transmission (patch) mode and monopole mode. This thesis is also supported 


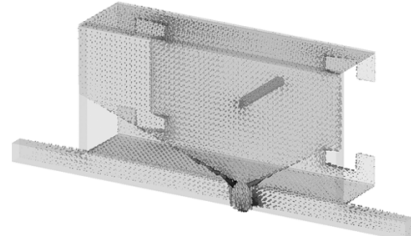

(a)

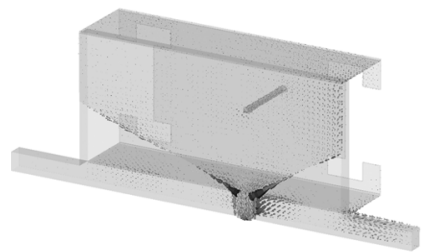

(c)

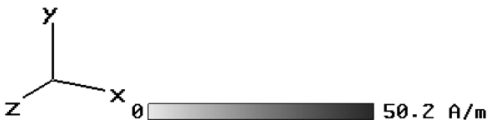

Fig. 7. Current distribution respectively at: (a) $3 \mathrm{GHz}$, (b) $6.85 \mathrm{GHz}$, (c) $8 \mathrm{GHz}$, and (d) $10 \mathrm{GHz}$.

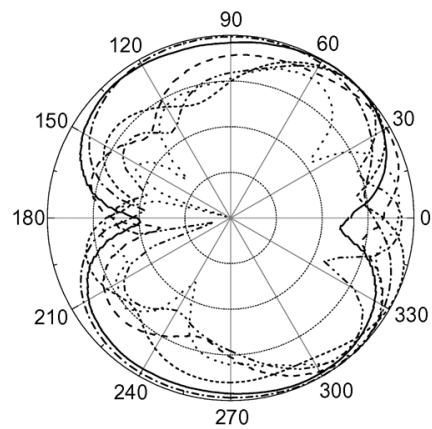

(Configuration A)

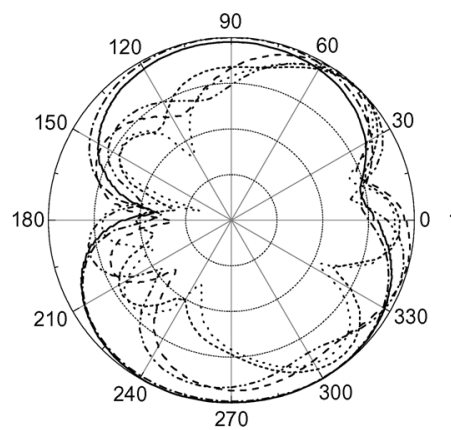

(Configuration $\mathrm{C}$ )

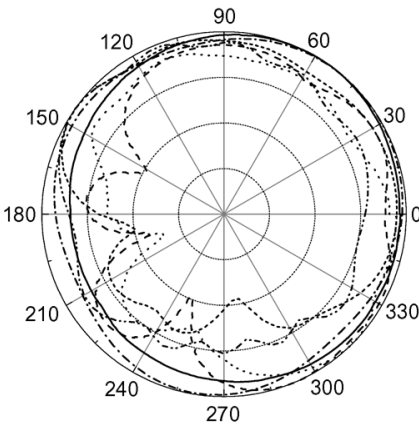

(Configuration B)

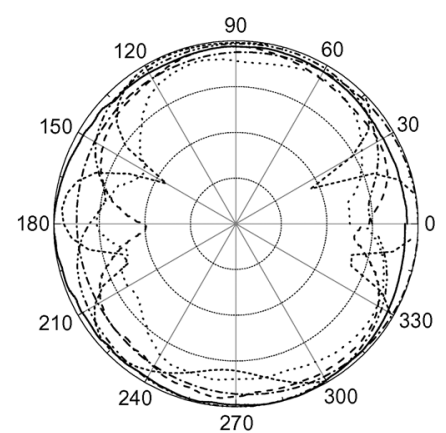

(Configuration D)

\footnotetext{
- Measured $\mathrm{E}-\phi$ at $3 \mathrm{GHz}$

-..-- Measured E- $\phi$ at $6.85 \mathrm{GHz}$

....... Measured $\mathrm{E}-\phi$ at $10 \mathrm{GHz}$

- - - Simulated $\mathrm{E}-\phi$ at $3 \mathrm{GHz}$

-..-Simulated $\mathrm{E}-\phi$ at $6.85 \mathrm{GHz}$

Simulated $\mathrm{E}-\phi$ at $10 \mathrm{GHz}$
}

$10 \mathrm{~dB}$ per division

Fig. 8. Radiation patterns for xy-cut at 3, 6.85 and $10 \mathrm{GHz}$.

by looking at the current distribution in the antenna displayed in Fig. 7 for frequencies of 3, 6.85, 8, and $10 \mathrm{GHz}$, respectively. From this, it is seen that a stronger current distribution exists on the walls of the external part, which are orthogonal to the ground plane. These currents confirm a significant electric field compo-
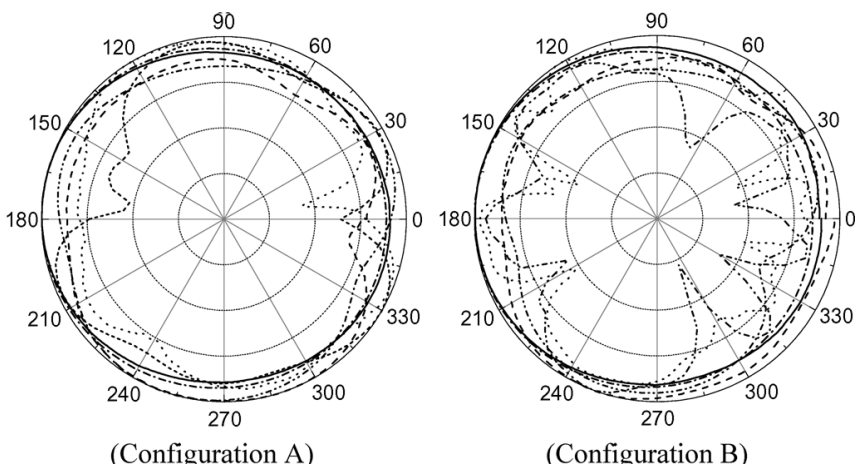

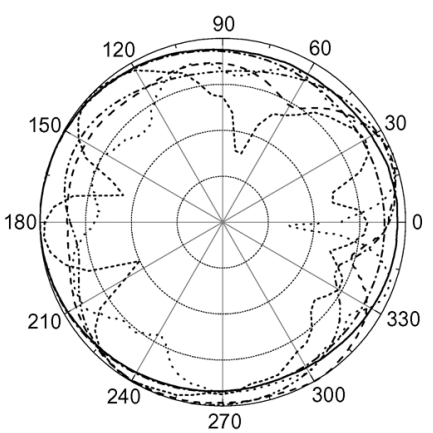

(Configuration $\mathrm{C}$ )

Measured $\mathrm{E}-\theta$ at $3 \mathrm{GHz}$

- - Measured $\mathrm{E}-\theta$ at $6.85 \mathrm{GHz}$

….... Measured $\mathrm{E}-\theta$ at $10 \mathrm{GHz}$

- - - Simulated $\mathrm{E}-\theta$ at $3 \mathrm{GHz}$

- - - Simulated E- $\theta$ at $6.85 \mathrm{GHz}$

- Simulated $\mathrm{E}-\theta$ at $10 \mathrm{GHz}$

$10 \mathrm{~dB}$ per division

Fig. 9. Radiation patterns for xz-cut at 3, 6.85, and $10 \mathrm{GHz}$.

nent pointing in the $y$ axis, which is characteristic of patch radiation. However, for higher frequencies the currents tend to be located more on the periphery and aligned with the $y$ axis. Consequently, the electric field presents reinforced components in the $x z$ plane, which is typical behavior of a monopolar antenna. Such a field configuration explains the deteriorated omnidirectionality of the radiation pattern in the $x z$-cut at higher frequencies. Another important aspect of the current distribution shown in Fig. 9 is the strong concentration in the slits cut out from the external metallic element. They resonate at the lower part of the spectrum and are transparent at higher frequencies.

Figs. 8-10 show the measured and simulated radiation patterns for the principle planes when the antenna is mounted at the various locations on the large ground plane according to the four configurations in Fig. 4. The frequencies investigated are $3,6.85$, and $10 \mathrm{GHz}$. The $x z$-cuts present good omnidirectionality in the lower part of the UWB spectrum even for the configuration $\mathrm{B}$, in which the antenna is mounted asymmetrically. However, at higher frequencies the patterns are more distorted and deep nulls appear as seen in xz-cuts at $10 \mathrm{GHz}$. From this last comparison, configuration $\mathrm{D}$ presents the most interesting radiation features as this pattern is reasonably regular.

\section{Dependence on the Ground Plane}

Due to the folded element, the proposed antenna presents an interesting independence from its position on the larger ground 

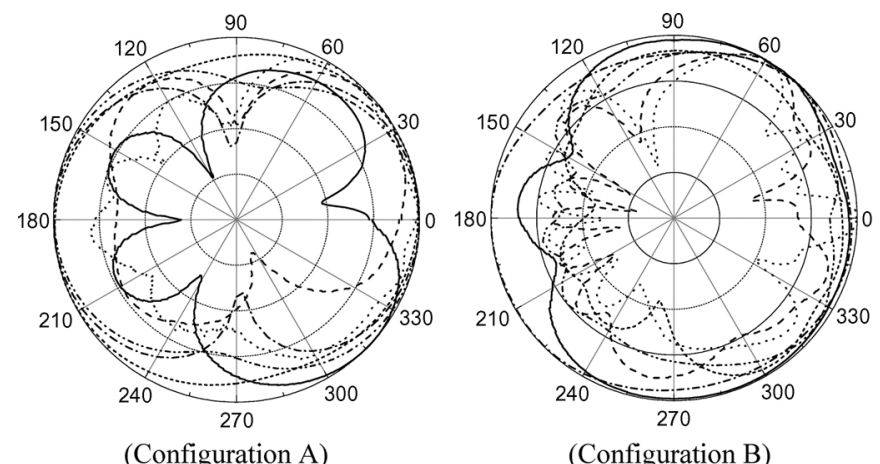

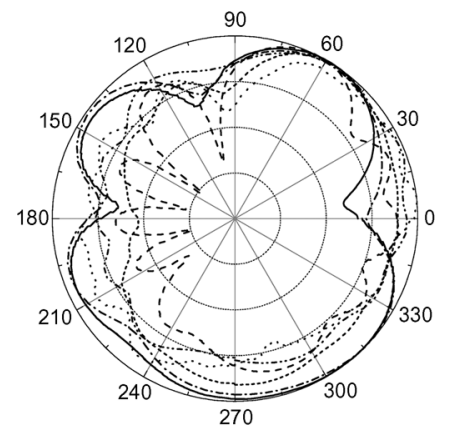

(Configuration C)

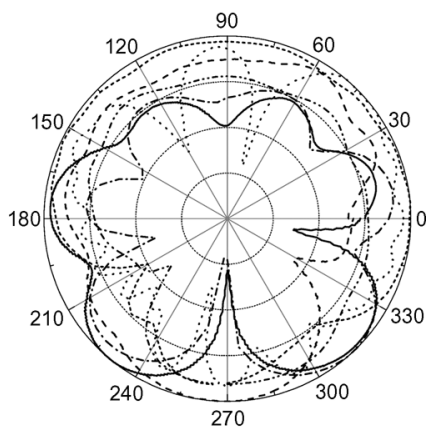

(Configuration D)

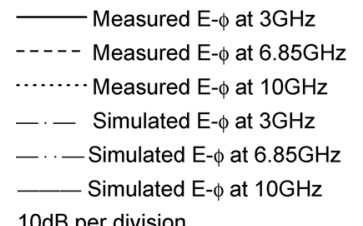

Fig. 10. Radiation patterns for yz-cut at 3,6.85, and $10 \mathrm{GHz}$.

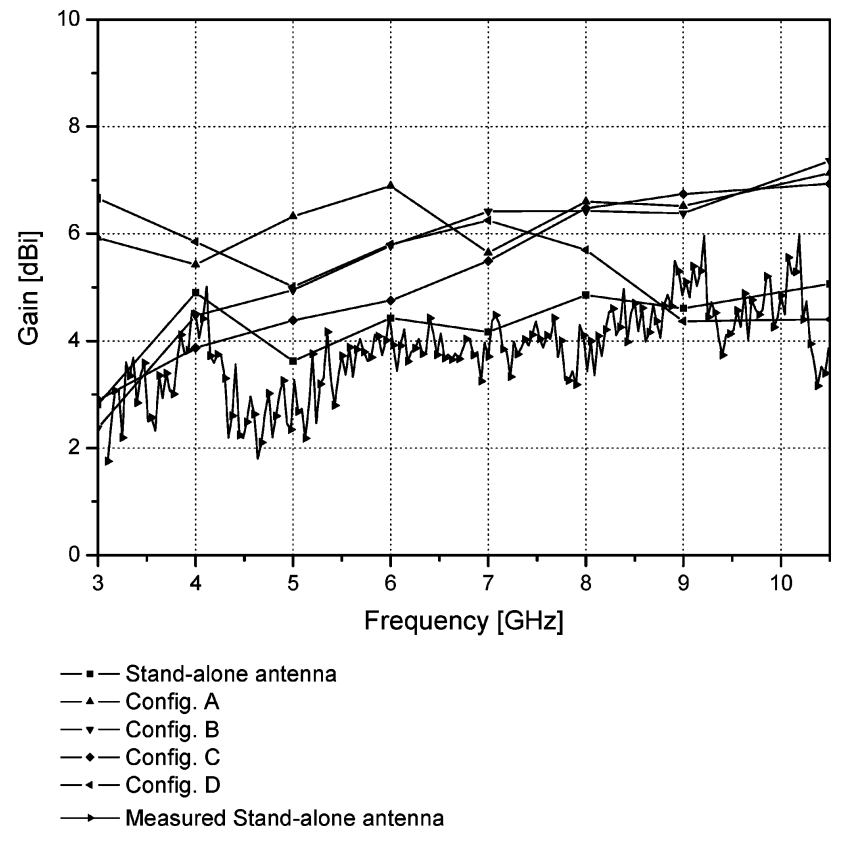

Fig. 11. Gain response for the various configurations analyzed.

plane. The external element behaves as a metallic box, within which the currents flow and change their distribution for different frequencies, with only minor effects observed on the radiated field. This feature explains a certain independence of

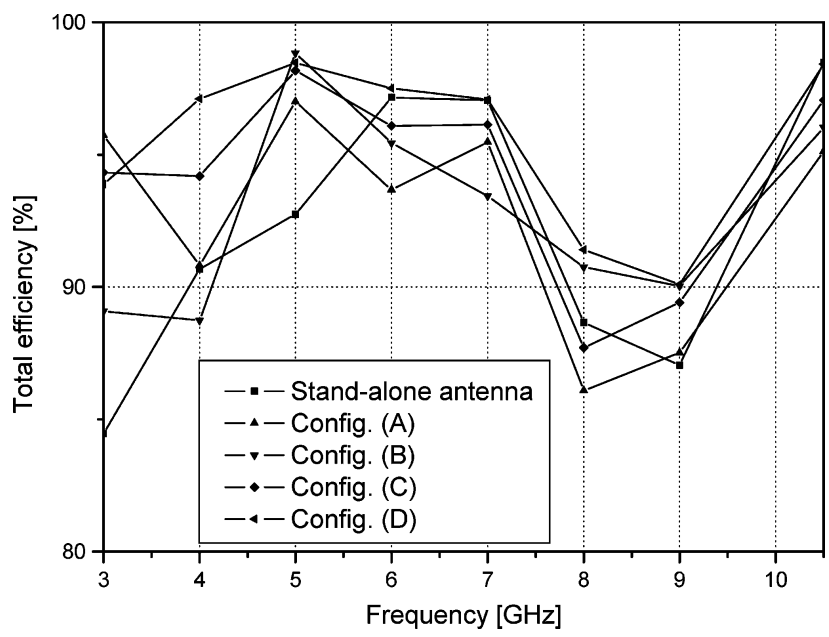

Fig. 12. Total efficiency response for the various configurations analyzed.

both impedance and radiation properties from the presence of a large groundplane and its position with respect to the antenna. Fig. 11 shows the simulated maximum gain response comparison for the different configurations investigated and the measured maximum gain of the stand-alone antenna. A good agreement between simulated and measured data has been achieved. As expected, when the large ground plane is introduced, the gain performance generally improves compared to the antenna in its stand-alone configuration (small ground plane). Moreover, besides some discrepancies at the lower part of the spectrum, the configurations analyzed present a gain response that follows the same behavior of the stand-alone antenna over the centre and upper end of the operating bandwidth. A similar tendency is observed for the total efficiency response in Fig. 12. In general, the total efficiency remains very high (better than $84 \%$ ) over the frequency range considered for all the configurations investigated. However, by analyzing all the sets of measurements taken on the different prototypes realizing the configurations in Fig. 4, the best location for the antenna was found to be configuration D (i.e., with the large ground plane extending the small one). Besides the reduced profile of this arrangement compared to the others, configuration D offers very large impedance bandwidth and decent radiation characteristics, especially at lower frequencies.

\section{CONCLUSIONS}

This paper presents the design and analysis of a compact folded shorted miniaturized antenna. The antenna combines the attractive features of PCB and PIFA technologies with those of asymmetry and beveling. Besides compactness and low cost manufacturability, the proposed antenna provides high efficiency and good omnidirectional radiation patterns which do not show heavy dependence on the presence of a large ground plane when mounted on it, in various arrangements. These features suggest that this antenna is suitable for future-generation UWB portable terminal/handset applications.

\section{REFERENCES}

[1] N. P. Agrawall, G. Kumar, and K. P. Ray, "Wide-band planar monopole antennas," IEEE Trans. Antennas Propag., vol. 46, no. 2, pp. 296-297, 1998. 
[2] M. J. Ammann, "Square planar monopole antenna," in Proc. Inst. Elect. Eng. Nat. Conf. Antennas Propagat., York, U.K., 1999, pp. 37-40.

[3] J. A. Evans and M. J. Ammann, "Planar trapezoidal and pentagonal monopoles with impedance bandwidths in excess of 10:1," in Proc. IEEE Int. Symp. Antennas Propagation, 1999, pp. 1558-1561.

[4] Z. N. Chen, "Broadband roll monopole," IEEE Trans. Antennas Propag., vol. 51, no. 11, pp. 3175-3177, 2003.

[5] P. Li, J. Liang, and X. Chen, "Study of printed elliptical/circular slot antennas for ultrawideband applications," IEEE Trans. Antennas Propag., vol. 54, no. 6, pp. 1670-1675, 2006.

[6] M. John and M. J. Ammann, "Spline based geometry for printed monopole antennas," Electron. Lett., vol. 43, no. 6, pp. 317-319, 2007.

[7] L. Virga and Y. Rahmat-Samii, "Low-profile enhanced-bandwidth PIFA antennas for wireless communications packaging," IEEE Trans. Microw. Theory Tech., vol. 45, no. 10, pp. 1879-1888, 1997.

[8] H. M. Chen, Y. F. Lin, P. S. Cheng, H. H. Lin, C. T. P. Song, and P. S. Hall, "Parametric study on the characteristics of planar inverted-F antenna," Proc. Inst. Elect. Eng. Microw. Antennas Propagation, vol. 152, no. 6, pp. 534-538, Dec. 2005.

[9] G. Ruvio and M. J. Ammann, "From L-shaped planar monopoles to a novel folded antenna with wide bandwidth," Proc. Inst. Elect. Eng. Microw. Antennas Propagation, vol. 153, no. 5, pp. 456-460, Oct. 2006.

[10] M. J. Ammann, "Control of impedance bandwidth of wideband planar monopole antennas using a beveling technique," Microw. Opt. Technol. Lett., vol. 30, no. 4, pp. 229-232, Jul. 2001.

[11] G. Ruvio and M. J. Ammann, "A compact wide-Band shorted folded antenna," in Proc. IEEE Int. Workshop on Antenna Technology, Small Antennas and Novel Metamaterials, Mar. 2006, pp. 84-87.

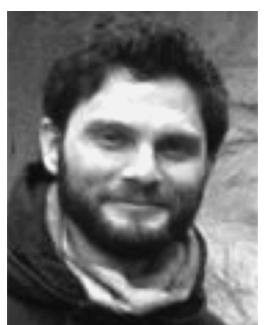

Giuseppe Ruvio (M'07) received the Laurea degree from the University of Siena, Italy, in 2002. He is currently working towards the Ph.D. degree at the School of Electronic and Communications Engineering, Dublin Institute of Technology, Ireland.

In 2002, he spent nine months at the Chalmers University of Technology, Sweden, where he worked on hard and soft surfaces and guided transmission applications based on them. From 2003 to 2004, he worked at the R\&D Department of Sigma Wireless Ltd., Ireland, in the framework of an ARTES 5 project on EBG base station antennas in collaboration with the European Space Agency. His current research interests include wide-band and UWB antennas and EBG antennas.

Mr. Ruvio's Ph.D. studies are financed by Science Foundation Ireland.

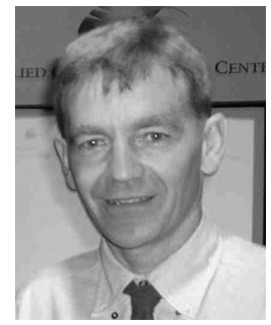

M. J. Ammann (M'96) received the Ph.D. degree in microwave antenna design from Trinity College, University of Dublin, Ireland.

$\mathrm{He}$ has eight years of industrial experience in radio systems engineering and antenna design with TCL/Philips Radio Communications Systems, Finglas, Dublin. He joined the School of Electronic and Communications Engineering, Dublin Institute of Technology, as a Lecturer in 1986 and was promoted to Senior Lecturer in 2003. He is the Director of the Antenna and High Frequency Research Group, currently comprising 12 members and also leads the antenna research within Ireland's Centre for Telecommunications Value-chain Research (CTVR). His research interests include electromagnetic theory, antenna miniaturization for terminal and ultrawideband applications, microstrip antennas, metamaterials, antennas for medical devices and the integration with photovoltaic systems. He has in excess of 100 peer-reviewed papers published in journals and international conferences.

Dr. Ammann became a Chartered Engineer and member of the Institution of Electrical Engineers (IEE), London, U.K., in 1986. He is a member of the IEEE International Committee for Electromagnetic Safety and participated in the revision of the IEEE Std C95.1, 2005 standard for Safety Levels with Respect to Human Exposure to Radio Frequency Electromagnetic Fields, $3 \mathrm{kHz}$ to $300 \mathrm{GHz}$. He is also a member of Communications and URSI Radio Science Committee of the Royal Irish Academy. He co-Chaired the Special Session on Antennas for UWB Wireless Communication Systems, IEEE APS, Columbus, Ohio, 2003 and was Track Chair for Antennas and Propagation for the 65th IEEE VTC, Dublin, Ireland, 2007. 